\title{
Mechanical Performance at Cryogenic Temperature of the Modules of the External Cylinder of CMS and Quality Controls Applied During Their Fabrication
}

\author{
S. Sgobba, C. D’Urzo, P. Fabbricatore, and S. Sequeira Tavares
}

\begin{abstract}
The CMS experiment (Compact Muon Solenoid) is a general-purpose proton-proton detector designed to run at the highest luminosity at the Large Hadron Collider (LHC). Distinctive features of the CMS detector include a high-magnetic-field solenoid (4 T) coupled with a multilayer muon system, a fully active scintillating-crystal electromagnetic calorimeter, a tile hadronic calorimeter, and a powerful inner tracking system. The superconducting solenoid ( $6 \mathrm{~m}$ diameter by $12.5 \mathrm{~m}$ long free bore) is enclosed inside a $10000 \mathrm{t}$ return yoke. The external cylinder of the CMS coil consists of five modules having an inner diameter of $6.8 \mathrm{~m}$, a thickness of $50 \mathrm{~mm}$ and an individual length of $2.5 \mathrm{~m}$. The cylinder shall feature a yield strength of $209 \mathrm{MPa}$ at its working temperature of $4.5 \mathrm{~K}$. The structural material selected for the components of the cylinders is the non heat-treatable aluminum alloy EN AW-5083. Each module of the cylinder is composed of a $50 \mathrm{~mm}$ thick shell, manufactured by bending and welding thick plates of strain hardened EN AW-5083-H321, of two $130 \mathrm{~mm}$ thick end flanges fabricated as seamless rolled rings and circumferentially welded to the shells, and of radial shoulders of the same alloy, to which the coil support system is attached through tie-rods. The components (seamless rings, plates, shoulders) and the manufacturing methods have been fully validated by a systematic assessment down to cryogenic temperature of the mechanical properties on samples issued from full scale parts, and by a rigorous qualification of the fabrication welds, performed on weld extra-lengths issued from each one of the modules.
\end{abstract}

Index Terms-Aluminum alloys, cryogenic material properties, MIG welding, ring rolling.

\section{INTRODUCTION}

$\mathbf{T}$ HE CMS experiment (Compact Muon Solenoid) is a general-purpose proton-proton detector of the LHC [1]. The superconducting solenoid $(6 \mathrm{~m}$ diameter by $12.5 \mathrm{~m}$ long free bore) of the CMS magnet is wound in an "external cylinder", used as an outer winding mandrel and a mechanical reinforcement structure. Each one of the five modules of the superconducting coil will be wound inside a module of the Al-alloy (AA) external cylinder. Each module of the cylinder, having an inner diameter of $6.84 \mathrm{~m}$ and a length of $2.53 \mathrm{~m}$ is composed of three elements (Fig. 1): a $50 \mathrm{~mm}$ thick shell, two $130 \mathrm{~mm}$ thick end flanges and radial shoulders to support the coil system through tie-rods. The central module has thicker end flanges $(180 \mathrm{~mm})$ that include shoulders for longitudinal tie-rods.

Manuscript received October 21, 2003.

S. Sgobba and S. Sequeira Tavares are with the CERN, CH-1211 Geneva, Switzerland (e-mail: Stefano.Sgobba@cern.ch).

C. D'Urzo is with Ansaldo Superconduttori, I-16152, Genova, Italy.

P. Fabbricatore is with INFN, I-16146, Genova, Italy.

Digital Object Identifier 10.1109/TASC.2004.829718

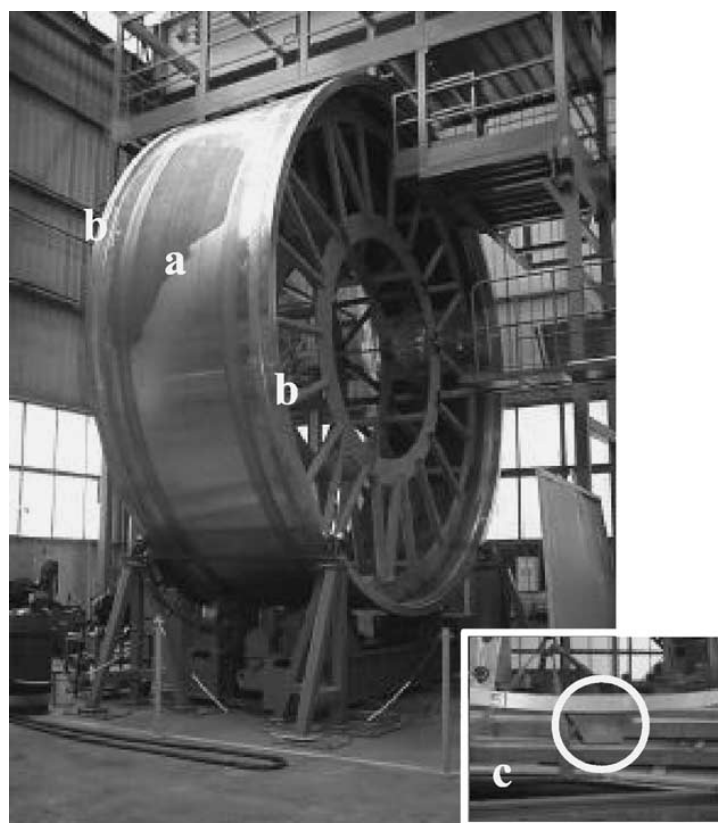

Fig. 1. Module of the external cylinder. Each module is composed of three elements: (a) a shell; (b) two end flanges; (c) shoulders for the tie-rods.

The ten end flanges have been successfully manufactured by ring rolling as seamless rings [2]. The shells have been obtained as a welded construction starting from plates $75 \mathrm{~mm}$ thick further reduced in thickness by machining after welding. The radial shoulders to be welded within the shells have been removed from a specially fabricated seamless ring. Contrary to the construction of cylinders of former solenoids (e.g. Delphi, Finuda, Babar) no stress relieving treatments have been applied to the modules. They would have reduced the mechanical properties and this would have been unacceptable for the present construction [3].

The cylinder shall feature a yield strength of $209 \mathrm{MPa}$ at its working temperature of $4.5 \mathrm{~K}$. In view of the severe constraints, the manufacturing methods have been validated by measuring the tensile properties down to cryogenic temperature on samples and welds removed from components constituting the real modules of the cylinder. The results of this assessment, at a very advanced state of production, are presented in this paper. The manufacturing and controls steps of the seamless rings for the end flanges, the forming and longitudinal welding of the shells and of the circumferential welding to the end flanges are detailed in a previous paper [2]. 


\section{Materials, Experimental Procedure, QUALITY CONTROLS}

The structural material selected for the components of the cylinders is the non heat-treatable AA EN AW-5083 [2], [3]. The ten end flanges are obtained from seamless rings produced by the firm Dembiermont (F) and delivered in the temper H116. The rings have been successfully submitted to a $100 \%$ visual and dimensional inspection and a $100 \%$ Ultrasonic Testing (UT) carried out according to ASTM B594. The company performed Room Temperature (RT) tensile and hardness tests on the rings according to ASTM B557 and E10, respectively, and an exfoliation corrosion test following ASTM G66-86.

With an internal diameter of $6.8 \mathrm{~m}$, the rings are, to our knowledge, the largest AA seamless rings ever produced.

The $75 \mathrm{~mm}$ thick plates used as base metal for the welded construction of the shells have been delivered in the temper H321 by Pechiney (F) and certified according to ASTM B209 which guarantees a minimum yield strength $R_{p 0.2}$ of $200 \mathrm{MPa}$ at RT.

Certified welders of Ansaldo Superconduttori (I) performed the longitudinal and circular welds by an automatic MIG technique using an EN AW-5183 filler wire with a diameter of $1.6 \mathrm{~mm}$ supplied by ESAB. Both circular and longitudinal welds follow the same Welding Procedure Specification (WPS) and are approved according to EN 288-4. In order to qualify the fabrication welds, an extra-length of the longitudinal weld (run-off or run-on plates of a length of $0.4 \mathrm{~m}$ ) have been supplied to CERN for each one of the modules. The welds have been approved by Metlab (FI) and CERN. Each extra-length has been successfully submitted to a complete welding procedure approval including $100 \%$ visual examination according to EN $970,100 \%$ dye penetrant examination according to EN 571-1, $100 \%$ UT according to EN 1714, transverse tensile testing according to EN 895, transverse side bend tests up to $180^{\circ}$ according to EN 910, macro- and microstructure examination according to EN-ISO 13919-2 and EN 1321.

A seamless ring with an internal diameter of $1.9 \mathrm{~m}$ and a cross section of $0.27 \mathrm{~m} \times 0.46 \mathrm{~m}$ has been rolled by Dembiermont in order to manufacture those of the shoulders that are not integrated into the thickness of a flange (see Section I). They are delivered in the temper H116 and submitted to the same inspections applicable to the largest rings.

On the rings and the weld extra-lengths of the shells, tensile tests at $4.2 \mathrm{~K}$ (and cross-check tests at RT) have been carried out at CERN on a special apparatus for high precision testing described in a previous paper [4]. Specimens of $9 \mathrm{~mm}^{2}$ square section with a calibrated length of $25 \mathrm{~mm}$ have been tested. Additional tests on plates at $4.2 \mathrm{~K}$ have been performed at CERN.

All materials are delivered with a certificate of type 3.1.B according to EN 10088.

\section{TENSILE PROPERTIES OF THE COMPONENTS OF THE EXTERNAL CYLINDER AND OF THEIR WELDS}

\section{A. Seamless Rings}

The tensile properties have been systematically measured on the ten produced rings. Fig. 2 shows the results obtained for the three main directions of the rings (longitudinal or rolling direction, axial, radial). At RT [Fig. 2(a)], mean and individual mea-

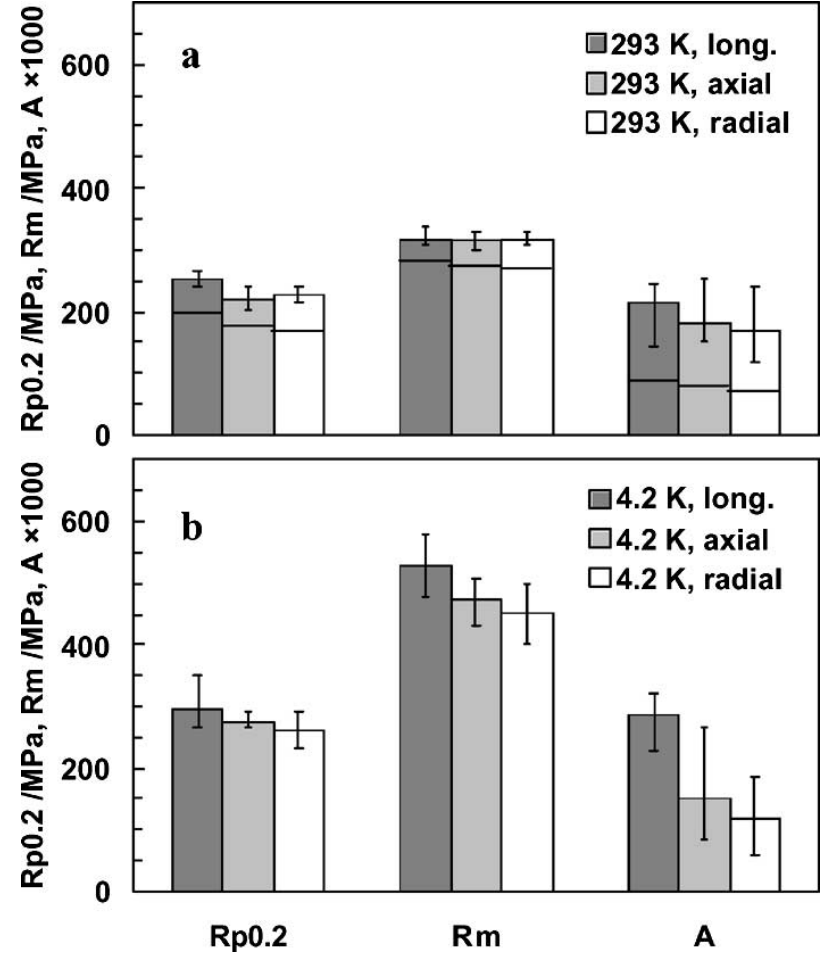

Fig. 2. Average tensile properties at RT (a) and $4.2 \mathrm{~K}$ (b) of the $6.8 \mathrm{~m}$ diameter seamless rings measured in the three main directions (the longitudinal is the one of maximum flow). Vertical bars show the range of the measured values around the mean value. Horizontal bars in Fig. (2a) refer to the minimum specified values. Symbols according to EN 10002-1.

sured values exceed the specified requirements. A remarkable isotropy of the tensile properties is achieved by ring rolling, as well as a very limited dispersion of both yield and tensile strength.

At $4.2 \mathrm{~K}$ [Fig. 2(b)], the average $R_{p 0.2}$ is close to $300 \mathrm{MPa}$ in the longitudinal direction where the maximum stress acts. This measured $R_{p 0.2}$ is safely above the design stress of $209 \mathrm{MPa}$ at $4.2 \mathrm{~K}$. In the other directions the minimum value of $R_{p 0.2}$ (measured in the radial direction) exceeds $230 \mathrm{MPa}$. The ductility in the longitudinal direction increases with decreasing $\mathrm{T}$ (the elongation at breakdown $A$ increases in average from $21.5 \%$ at RT to $28.7 \%$ at $4.2 \mathrm{~K}$ ), while in both transverse directions (axial and radial) a strain at breakdown over $6 \%$ at $4.2 \mathrm{~K}$ is maintained in any case.

\section{B. Welded Shells}

The tensile properties of the welds and of the base material at RT and $4.2 \mathrm{~K}$ are presented in Fig. 3 and Fig. 4, respectively.

At RT, an adequate number of tensile samples have been tested in order to fully cover the thickness of the weld. At $4.2 \mathrm{~K}$, two sets of seven specimens are distributed in the thickness of the weld (and, for comparison, of the base material) in order to assess the distribution of the tensile properties over the weld thickness. Due to the limited thickness of $4.2 \mathrm{~K}$ tensile samples (see Section II), it would be impractical to cover the full thickness.

At RT (Fig. 3), the tensile strength $R_{m}$ of the different tested welds is at any point above the minimum strength specified of the base metal in the annealed state $(270 \mathrm{MPa})$, as required by 


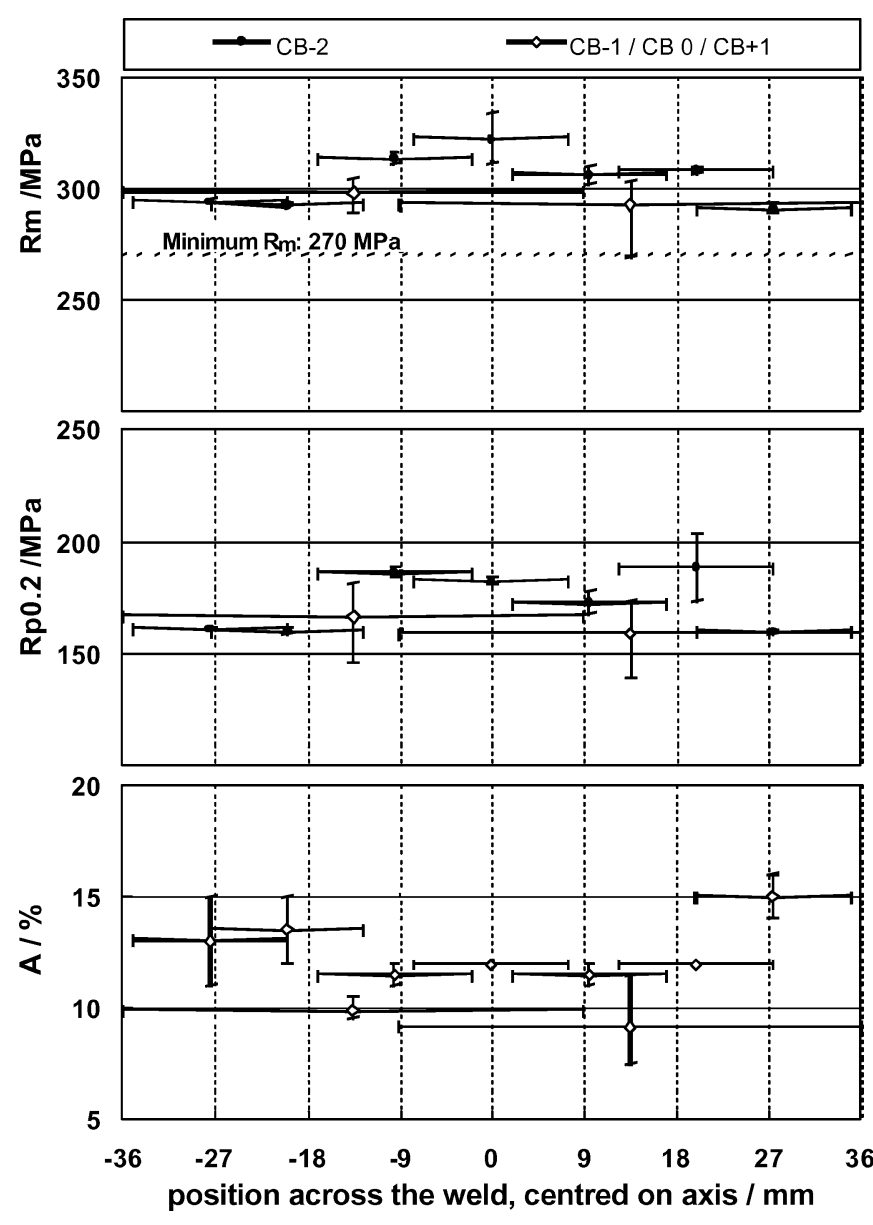

Fig. 3. Tensile properties at RT of the longitudinal welds of module CB-2 (two series of five specimens across the thickness) and CB-1, CB 0, CB+1 (two series of two specimens across the thickness), measured on weld extra-lengths. The average value per specimen position is plotted. Vertical lines range between the minimum and maximum measured values. Horizontal lines represent the thickness of the specimen.

EN 288-4. Elongation at breakdown $A$, when measured, is in average above $10 \%$.

At $4.2 \mathrm{~K}$ (Fig. 4), the mean $R_{p 0.2}$ at any point is safely above the design stress of $209 \mathrm{MPa}$ and, by averaging on the thickness, is above the minimum specified strength of $225 \mathrm{MPa}$. The results at $4.2 \mathrm{~K}$ indirectly confirm the soundness of the weld, as deduced by nondestructive tests and micro-optical inspections. Indeed, possible local defects (cracks, gas cavities...) present in the calibrated length of the tensile test sample, would impair the performance of the weld. Due to the small cross section of individual samples $\left(9 \mathrm{~mm}^{2}\right)$, they would induce poor tensile strength or ductility.

\section{Shoulders}

The tensile properties measured in the three main directions of the $1.9 \mathrm{~m}$ diameter ring where the shoulders were removed are summarized in Table I. Minimum required properties are the same as the minimum tensile properties specified for the extremity rings. As for the larger rings, the properties of the shoulders are well above specification at RT. At $4.2 \mathrm{~K}$, the $R_{p 0.2}$ is safely above the design stress of $209 \mathrm{MPa}$. This is particularly important for the shoulders, where the maximum stress acts.
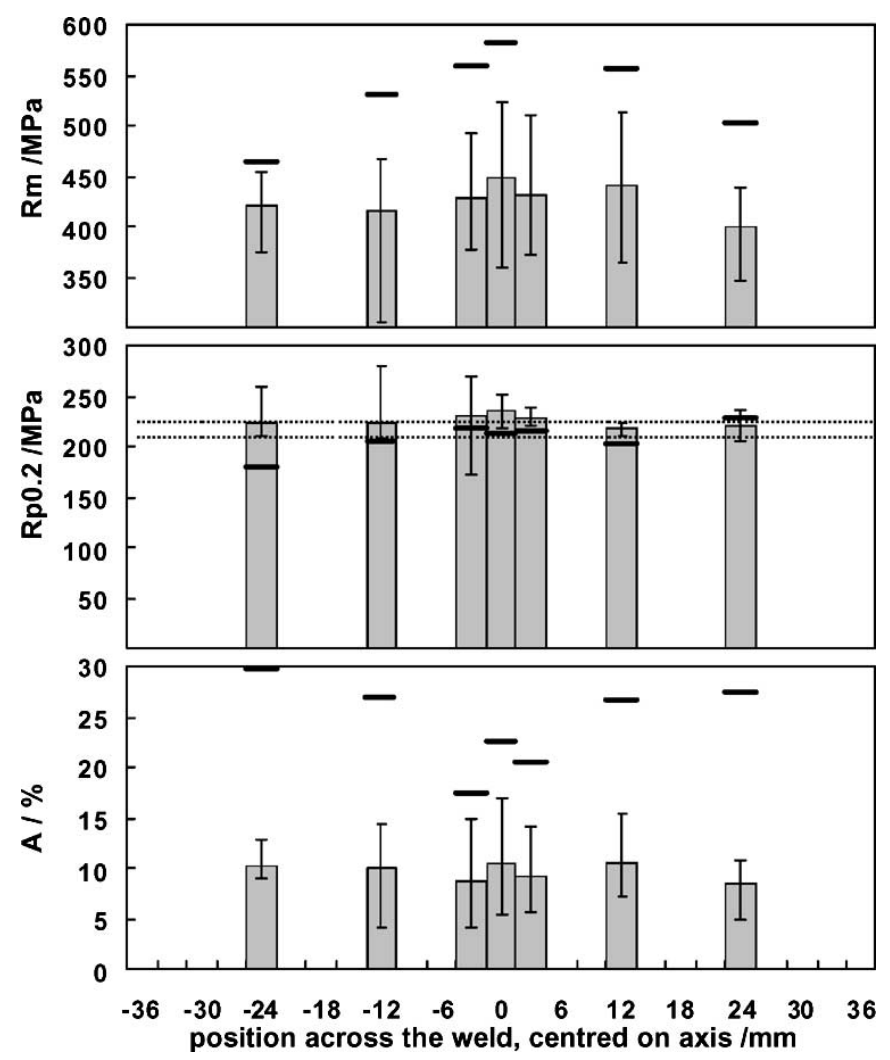

Fig. 4. Tensile properties at $4.2 \mathrm{~K}$ of the longitudinal welds of modules CB-2, $\mathrm{CB}-1, \mathrm{CB} 0$ and $\mathrm{CB}+1$ (two series of seven specimens over the thick-ness), measured on weld extra-length. The mean value per position is plotted. Vertical lines refer to minimum and maximum measured values. The width of the bars represents the thickness of the specimens. The short horizontal lines, plotted for comparison, are the values obtained for the base metal at the same position. The dashed lines represent the minimum specified value for $R_{p 0.2}$ and the design stress at 4.2 K (225 MPa and $209 \mathrm{MPa}$, respectively).

TABLE I

TENSILE Properties OF THE SHOULdERS’ Ring

\begin{tabular}{lllll}
\hline \hline Direction & $\begin{array}{l}\mathrm{R}_{\mathrm{p} 0.2} / \mathrm{MPa}, \\
\text { measured } \\
\text { (specified) }\end{array}$ & $\begin{array}{l}\mathrm{R}_{\mathrm{m}} / \mathrm{MPa} \\
\text { measured } \\
\text { (specified) }\end{array}$ & $\begin{array}{l}\mathrm{A} / \%, \\
\text { measured } \\
\text { (specified) }\end{array}$ & $T / K$ \\
\hline Longitudinal & $224(200)$ & $306(285)$ & $22.2(9)$ & 293 \\
Axial & $196(180)$ & $294(275)$ & $18.0(8)$ & 293 \\
Radial & $199(170)$ & $303(270)$ & $15.8(7)$ & 293 \\
& & & & \\
Longitudinal & $261(-)$ & $536(-)$ & $30.1(-)$ & 4.2 \\
Axial & $240(-)$ & $509(-)$ & $24.8(-)$ & 4.2 \\
Radial & $230(-)$ & $456(-)$ & $15.1(-)$ & 4.2 \\
\hline \hline
\end{tabular}

Measured (specified) tensile properties at RT and $4.2 \mathrm{~K}$ of the seamless ring where the radial shoulders have been removed. Average values.

Ring rolling, followed by a final cold expansion conferring the adequate mechanical properties to the ring by cold stretching, was advantageous for the production of the shoulders compared to open die forging. In order to achieve tensile properties higher than for the basic "as fabricated" or "annealed" temper and to maintain the required ductility, forging a non heat-treatable alloy such as EN AW-5083 requires a controlled warm reduction or a final cold forging. This is less straightforward to apply than a controlled stretching by expansion. 


\section{DISCUSSION}

Almost all large, indirectly cooled solenoids constructed before CMS have consisted of AA cylinders made up of bent plates, TIG or MIG welded. Intermediate thermal treatments of stress relieving were applied during fabrication to relax the stress of the cylinders and were necessary to fulfill the requirements of geometrical tolerances. The size and the level of stress of the cylinder of CMS, which shall feature a $R_{p 0.2}$ of $209 \mathrm{MPa}$ at $4.2 \mathrm{~K}$, imposed to avoid any stress relieving despite the severe geometrical tolerances. Its construction required:

1) A careful selection of alloy (EN AW-5083) and a high strength temper (H321 or H116).

2) The application of new manufacturing options to obtain high strength components (seamless rings including longitudinal shoulders, radial shoulders manufactured from a strain hardened ring).

3) The optimization of the welding procedures. These resulted in high strength joints, showing high performance and ductility down to $4.2 \mathrm{~K}$.

The tensile properties achieved on the extremity rings and the shoulders match the specified H116 temper. This temper state, achieved with a controlled expansion of the ring, allowed at the same time the required ductility to be maintained. The improved isotropy of the tensile properties and the high ductility in the three directions are clear advantages of ring rolling compared to rolling of plates, resulting at $4.2 \mathrm{~K}$ in values of $R_{p 0.2}$ safely above $209 \mathrm{MPa}$ and high values of strain at failure.

Thanks to a MIG welding procedure optimized for the construction of the shells, all the tested fabrication welds fulfill or exceed the requirements of EN 288-4, usually imposed for qualification welds. They show at $4.2 \mathrm{~K}$ values of $R_{p 0.2}$ above $209 \mathrm{MPa}$. Moreover, the selected welding procedure allowed a final stress relieving to be avoided, through a proper succession of alternating runs, accompanied by systematic dimensional checks after each run and a final nonsymmetric machining of the over-thickness. The comfortable over-thickness $(25 \mathrm{~mm}$ on the shell plates) has helped to obtain the final dimensional tolerances by machining alone.

\section{CONCLUSION}

The critical selection of components (seamless rings, plates, shoulders), manufacturing methods and welding techniques together with a rigorous and systematic qualification of the materials and fabrication procedure, allowed modules of the external cylinders to be constructed with high performance in terms of strength and ductility. Their tensile properties exceed at RT the specified requirements and show a $4.2 \mathrm{~K}$ yield strength safely above the required $209 \mathrm{MPa}$. The presented results, arising from a systematic assessment down to cryogenic temperature of the mechanical properties on samples issued from parts of real components and welds, confirm the adequacy of the applied technical solutions and the quality of the fabrication.

\section{ACKNOWLEDGMENT}

The authors acknowledge the assistance of M.L. Delsante and P. El Kallassi for tensile testing. The continuous and encouraging support of the CERN-CMS collaboration was greatly appreciated, in particular of A. Hervé, D. Campi and A. Gaddi.

\section{REFERENCES}

[1] A. Herve et al., Status of the Construction of the CMS Superconducting Magnet at LHC, , this conference.

[2] S. Sgobba et al., "Design, construction and quality tests of the large Al-alloy mandrels for the CMS coil," IEEE Trans. Appl. Supercond., vol. 12, no. 1, pp. 428-431, March 2002.

[3] M. Castoldi et al., "Possible fabrication techniques and welding specifications for the external cylinder of the CMS coil," IEEE Trans. Appl. Supercond., vol. 10, no. 1, pp. 415-418, March 2000.

[4] Proc. of the 4th European Conf. on Advanced Materials and Processes, vol. F, Venice-Padua, Italy, 1995, p. 153. 